\title{
Mujeres musulmanas situadas en torno al poder
}

\author{
Paulina lópez Pita *
}

\section{RESUMEN ABSTRACT}

Aunque sabemos que en el Islam

la mujer, en términos generales, estaba excluida del poder, encontramos haciendo un breve repaso en el Islam medieval que muchas mujeres desempeñaron un papel político de cierta importancia, de manera especial, entre las dinastías nacidas en Asia Central. Asimismo, fueron también numerosas las mujeres que ejercieron una notable influencia en

el gobierno tanto a través de sus maridos como actuando como regentes de sus hijos en al-Andalus $y$ en el norte de África. Es por tanto a estas mujeres que ejercieron el poder entre los musulmanes a las que dedicamos estas líneas.
Although it is known that in the Islamic world, women in general, couldn't access to power, we find that looking back at the middle age period, women didn't only participate in military campaigns, but as well they played their role of certain importance in politics, specially among dynasties coming from Central Asia. At the same time, there were a number of women who had influence in the political power, both acting through their husbands, and as regents of their children in $\mathrm{Al}-$ Andalus, and in North Africa. Therefore, we dedicate the following text to these women with political power among the Muslims.

A pesar de que el verdadero Islam no discrimina a las mujeres, en el mundo islámico, por regla general, la mujer está excluida del poder. No

* UNED. 
obstante, si hacemos un breve repaso a la historia del Islam medieval, encontramos que fueron numerosas las mujeres que de una $u$ otra forma estuvieron ocupando un lugar destacado en la vida política. Por ello voy a dedicar unas líneas a recordar a algunas de aquellas mujeres que desempeñaron funciones que, en principio, les estaban encomendadas a los hombres.

Algunas fueron famosas por su participación activa en las luchas políticas y en las guerras, tanto en la época preislámica como en la islámica, e incluso, como ahora señalaremos, durante la vida del Profeta Mahoma. Otras mujeres llegaron a ocupar el gobierno en algunos lugares donde el Islam se extendió; normalmente, como consecuencia del matrimonio contraído establecieron una estrecha relación con el poder a través de su esposo, o posteriormente, al quedarse viudas actuaron como regentes de sus hijos hasta que éstos pudieron gobernar. Ellas gobernaron como hombres, asumiendo las responsabilidades políticas que el ejercicio del poder llevaba consigo.

Hay que tener presente que el desconocimiento que tenemos sobre este tema se debe, en gran medida, a la carencia de fuentes, ya que la mayor parte de los textos fueron escritos por los hombres por lo que la imagen que nos llega a través de ellos responde a los patrones de una sociedad en la que las mujeres carecen de voz propia, recordemos que este hecho no es privativo de la cultura islámica.

A pesar de lo que comúnmente se cree, los primeros historiadores musulmanes dedicaron en sus trabajos una especial atención a las mujeres, no sólo como madres o hijas de un personaje importante, sino por su participación en hechos históricos importantes como lo fue el nacimiento del Islam. Incluso algunos de estos historiadores llegaron a desarrollar un género específico dedicado a la mujer, llamado "Ajbar an-Nissa" (Noticias de mujeres). Ibn Sa'ad (m.852) en su extensa obra "At-Tabqat al-Kubra" en la que relata la vida del Profeta y recoge biografías de sus compañeros más importantes, dedica el último volumen enteramente a las mujeres. Lo mismo ocurre en la obra de Tabari (839-923) "Tarij al-Umam wa-I-Muluk" (Historia de naciones y reyes), donde aparecen biografías de las discípulas y seguidoras del Profeta y de mujeres que participaron activamente en los primeros momentos para imponer el Islam. ${ }^{1}$

No obstante, la fuente primordial de la ley islámica y base de toda la normativa por la que debe regirse el musulmán es EI CORÁN, y es preci-

1 Cfr. MernissI, F.: El poder olvidado, pp. 163. 166, 171. 
samente en este Libro donde encontramos el primer ejemplo de una mujer con responsabilidad política, como es el caso de Bilqis, la conocida reina de Saba ${ }^{2}$. Hija única del monarca yemení heredó el reino, cuya capital estaba cerca de la actual Sana, a la muerte de su padre. De ella, aunque sin ser nombrada, (Sura 27: 23), habla el Corán favorablemente y menciona la manera en la que consultaba a sus consejeros, quienes acataron su decisión sobre la forma de tratar la amenaza de invasión del ejército de Suleymán, pues con buen juicio decidió enviar regalos y visitarle; ella misma dijo: "Oh señor, he sido injusta conmigo misma, pero me someto, junto con Suleyman, al Señor de los mundos» (Sura 27:44). ${ }^{3}$ Los comentaristas afirman que Salomón la confirmó como dirigente de su reino, por lo que en El Corán no se encuentra ninguna objeción a que la mujer actúe como gobernante ${ }^{4}$.

Posteriormente, durante la vida de Mahoma y de sus Compañeros, encontramos la primera muestra de intervención de las mujeres en la vida política cuando se firmó el "Pacto de Aqaba", desfiladero no muy lejano a La Meca, donde los habitantes de Medina, acordaron proteger y ayudar al Profeta, así lo refiere Ibn Sa'd:

"Durante la noche en que se acordó el compromiso de Aqaba, los hombres estrecharon la mano del Profeta... Umm Mani y yo permanecimos alli. Entonces mi marido, 'Arafa ibn 'Amr dijo en voz alta "Mensajero Allah, estas dos mujeres están aqui con nosotros para jurarte lealtad". A lo que el Profeta respondió: "Acepto su lealtad de la misma manera que la acepté de ti, pero no estrecho la mano de las mujeres".

Asimismo, las mujeres participaron en la guerra y mantuvieron una actividad militar. Al igual que ocurrió en los tiempos preislámicos en los que la mujer participó en los enfrentamientos tribales, posteriormente, al hacerse musulmanas continuaron luchando al lado del Profeta. Un hadiz las autoriza para poder actuar como auxiliares y enfermeras; algunas mujeres solían llevar agua y curaban a los heridos en las batallas, como hay constancia que lo hizo Layala al-Ghifariyya. ${ }^{5}$ Así como también participaron las propias mujeres de Mahoma: 'A'isa y Umm Sulaym, según lo re-

\footnotetext{
2 Esta reina pertenecía a la jahiliyya, época de la ignorancia. Tiempo anterior a la llegada del Profeta Mahoma y a la revelación de El Corán.

3 Salomón había oído decir que la reina de Saba tenía piernas velludas, para salir de dudas se valió de un ardid: colocó un pavimento de cristal en el suelo que la reina confundió con agua, por lo que se levantó la falda para pasar sin mojarse y asi dejó al descubierto las piernas. Cfr. J. CORTÉs, El Corán, p. 459.

4 Cfr. Bewley, A.: Islam: El poder de las mujeres, pp. 38-39.

Cfr. BEWLEY, A: op. cit., p. 40.
} 
fiere al-Bujari en su "Libro de las Expediciones", en los diversos capítulos en los que hace referencia a la participación de las mujeres en las guerras. En uno de éstos recoge la narración sobre lo sucedido en la batalla de Uhud, que tuvo lugar en una llanura frente a Medina, el 25 de marzo del año 625, en la que los seguidores de Mahoma fueron derrotados, y dice:

"Vi a 'A'isa y a Umm Sulaym con los vestidos recogidos. Podía ver sus tobillos. Llevaban los odres de agua a la espalda. Más tarde volvieron $y$ los llenaron de nuevo. Luego los vaciaron en las bocas de la gente».

También tenemos noticias de que en esta batalla participaron muchas mujeres de la tribu de Qurays, quienes caminaban en la retaguardia, animando a los guerreros tocando el tambor y recitando algunos versos. ${ }^{6}$

Pero sabemos que las mujeres no se limitaron a ir al campo de batalla para atender a los heridos. Otras como Safiyya bint 'Abdul-Muttalib y Nusayba lucharon y mataron al enemigo para defenderse ellas mismas y al Profeta, incluso llegaron a recibir botín, una vez finalizada la lucha, al igual que los hombres. La descripción de lbn Hisham, que escribió una importante biografía del Profeta, de la batalla de Uhud, lo demuestra claramente. Así, encontramos que Nusayba bint Ka'b, que estuvo presente en el juramento de Aqaba, luchó en defensa del Profeta cuando sólo quedaba un puñado de gente con él, y refiere que cuando Mahoma se dio cuenta de que ella no tenía escudo y vio a un hombre que llevando el suyo consigo se retiraba, dijo al hombre: "Entrega tu escudo a quien todavía está luchando", y señaló a Nusayba quien luchó hasta que fue herida.

Mahoma mantuvo una vieja costumbre de la yahiliyya y solía ir acompañado por alguna de sus mujeres cuando salía de Medina. Antes de emprender viaje decidía por sorteo cual de ellas le debía acompañar. Cuando decidió enfrentarse con los Banu Mustaliq, la suerte recayó en 'A'isa, la predilecta de Mahoma. Pero poco después de que tuviese lugar la conocida "Batalla del Foso", handaq, (627) tuvo lugar un desagradable incidente que proporcionó a historiadores y teólogos inagotable materia para todas las interpretaciones posibles. Sucedió que en una de las paradas que hicieron cerca de Medina, 'A'isa quedó rezagada buscando un collar que había perdido y quienes portaron su palanquín, no la echaron en falta, pues ella era muy ligera, y nadie se percató de que se había quedado atrás hasta que al día siguiente se la vio llegar al campamento en compa-

6 Pueden leerse estos versos citados en Galmés de FUENTES, A.: La épica románica y la tradición árabe, p. 368. 
ñía de un mozo que la había recogido. Se desataron las lenguas, y parece ser que fue 'Alí, uno de los que aconsejaron a Mahoma que dejase a 'A'isa y se buscara otra mujer. De aqui nace la mortal enemistad de 'A'isa contra 'Alí, factor importante, posteriormente, en la primera guerra civil y en la primera escisión político-religiosa del islam. ${ }^{7}$

La presencia habitual de las mujeres en la lucha nos explica la participación de 'A'isa, ya muerto Mahoma, en la «Batalla del Camello» (656), llamada así porque se combatió principalmente en torno al camello en que iba 'A'isa animando a los suyos. Recordemos que fue uno de los incidentes principales de la guerra civil, fitna, en el que las fuerzas de 'Alí derrotaron a los seguidores de 'A'isa, a las afueras de Basra. Se cuenta que 'Alí dijo al finalizar el episodio: "Si una mujer pudiera ser califa, 'A'isa lo habría sido". ${ }^{8}$

Un año después de la Batalla del Camello, tuvo lugar la «Batalla de Siffin", en la que participaron numerosas mujeres tanto entre los partidarios de 'Ali, como entre los de Mu'awiyya. Las mujeres ayudaban a los combatientes a colocarse la armadura y obligaban a regresar al combate a aquellos que pretendian huir ${ }^{9}$. Recordemos que, según la tradición, cuando iban ganando los partidarios de 'Alí, 'Amr tuvo la idea de poner en la punta de algunas lanzas un ejemplar del Corán, como mudo símbolo de apelación al juicio de Allah, muchos de los seguidores de 'Alí se retiraron, pero luego se arrepintieron y quisieron reanudar la lucha, ante la negativa de 'Alí, se separaron, y recibieron la denominación de "jariyíes", los que se salen.

Durante las conquistas de Iraq se produjo un incidente en el que la actuación de las mujeres tuvo una enorme importancia. Al ser atacado el campamento base en el que se hallaban las mujeres, una de ellas, temiendo que el ejército enemigo fuera demasiado fuerte para el ejército musulmán, ideó un plan para hacer creer al enemigo que habían recibido ayuda. Las mujeres hicieron banderas con sus pañuelos y bajo su dirección, marcharon cantando poemas por la victoria del Islam. Cuando llegaron al campo de batalla, el enemigo creyó que habían llegado los refuerzos y se retiró.

En las fuentes árabes aparecen diversas referencias a la actuación de estas «mujeres guerreras», como es el caso de la princesa al-Kahina,

Sobre 'A'isa existe una biografía escrita por Zahiya Moustapha Khaddoura, autora libanesa, escrita en los años cuarenta y reeditada en los años setenta,cfr. F. MERNISSI, El poder olvidado, $p$. 165.

9 Cfr. BEWLEY, A.: op cit. p. 45.

9 Cfr. Galmés de Fuentes, A.: op. cit. p. 370. 
quien alcanzó su fama por la importante resistencia que presentó junto a las tribus beréberes frente a la expansión árabe en el norte de África a finales del siglo VII, después de la caída de Cartago ${ }^{10}$. Llegó a dominar gran parte del Magreb ${ }^{1 t}$.

Así pues, aunque no existe un veredicto coránico acerca del lugar de las mujeres en el campo de batalla, ya sea en la línea militar o en la retaguardia, ni el Profeta ni sus Compañeros se opusieron a su presencia, e incluso les dieron permiso para que se unieran a la lucha. Esto incrementa el acuerdo de su legitimidad.

Por otra parte, y por lo que respecta al papel desempeñado directamente por la mujer en el ejercicio del poder, hay que tener presente que a pesar de que a la mujer se la excluye del poder político según un hadiz del Profeta recogido por Bujari, que dice: "la comunidad que instale a una mujer como gobernante fracasará" ${ }^{12}$, algunas mujeres han ejercido de facto el poder en tiempos medievales ${ }^{13}$. A lo largo de la historia del Islam muchas mujeres han ocupado cargos de importancia y liderazgo, pero además existen numerosos casos de mujeres gobernantes que adquirían el poder tras la muerte de sus maridos o que regían en su ausencia. Esto ocurrió especialmente entre las dinastías nacidas en Asia Central: selyuqies, mongoles, mamelucos o los primeros otomanos.

Siguiendo, a grandes rasgos, un orden cronológico, no podemos dejar de recordar en primer lugar el importante papel desempeñado por la mujer en las primeras décadas del Islam, y entre ellas debemos hacer referencia a algunas de las mujeres del Profeta: Jadiya, 'A'isa, Zaynab bint Jahch o Umm Salma, modelo de inteligencia razonada y en calma, que ocuparon un importante puesto en la vida política y estuvieron relacionadas con el poder. De Jadiya dijo Mahoma que era la mejor mujer de todo su tiempo, mientras vivió ella no contrajo matrimonio con ninguna otra mujer, en ella encontró madurez de espíritu, inteligencia, magnanimidad y una gran experiencia de la vida. Fue, sin embargo 'A'isa la que desempeñó un importante papel político en las confrontaciones internas en torno a la sucesión del Profeta. 'A'isa era hermosa, inteligente e intrigante. Destacó por

10 Cfr. Viguera, M. a J.: «Reflejos cronísticos de mujeres andalusíes y magrebíes», en Anaquel de Estudios Árabes, 12, p. 832.

11 Cfr. Galmes de Fuentes, A.: op. cit. p. 385

12 Parece ser que este hadiz fue difundido por los adversarios de 'A'isa para oponerse a su influencia política. Cfr. FIERRO, I.: “La mujer y el trabajo en el Corán y el Hadiz", en La mujer en Al.

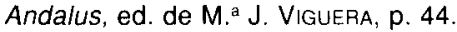

13 En el siglo xx, (16-nov.1988) Pakistán fue el primer pais musulmán que eligió a una mujer como primera ministra, Benazir Bhurto. 
su gran sabiduría acerca de la religión. Los Compañeros del Profeta afirmaban que cada vez que se encontraban con alguna dificultad ante un hadiz, se dirigian a 'A'isa quien a través de su explicación les mostraba que lo conocía con detalle. A ella acudían personas de las tierras más recónditas por su conocimiento de la sunna y de aquello que era obligatorio. Transmitió su conocimiento a por lo menos 77 hombres y 8 mujeres.

Pero esto no sólo ocurría con 'A'isa, también era el caso del resto de las mujeres del Profeta y de otras mujeres que vinieron después, como fue el caso de Amra bint Abdu'r-Rahman, cercana a 'A'isa que solía dar su opinión sobre aspectos legales a la generación que siguió a los Compañeros del Profeta. Fue la experta más destacada sobre las transmisiones de 'A'isa. Incluso se piensa que fue una mujer, Umm Waraqa, la que ayudó a 'Umar a reunir todos los textos que componen El Corán. Parece ser que Umm Salma requirió al Profeta aclaraciones sobre el texto revelado, y Mahoma que escuchaba a las mujeres, la respondió con el versículo 25 en el que se reconoce a la mujer su estatuto de copartícipes, implicadas al igual que los hombres en el proceso de revelación ${ }^{14}$.

En época del Profeta y de los califas ortodoxos, las mujeres tuvieron un papel determinante en la política, fueron, entonces, las mujeres de la aristocracia árabe las que van a aparecer en torno al califa, actuando como esposas y madres de califas y príncipes. Más tarde, la expansión del Imperio trajo consigo un aumento de esclavas de todos los países conquistados, por lo que en época de los califas 'abbasies triunfaron las esclavas, que serán las únicas a quienes se admita en torno al califa. Las esclavas tenían una procedencia muy diversa e influyeron profundamente en sus hijos, maridos o en quienes las rodeaban. Muchas de ellas fueron elevadas al rango de esposas y madres. La mayoría de los califas 'abbasies eran hijos de esclavas.

Durante el gobierno de los 'Abbasíes, encontramos a una mujer con gran vocación política como fue Jayzuran, quien había nacido libre en el Yemen pero llegó a Bagdad como esclava ${ }^{15}$. Dio muestras de un gran talento durante el tiempo que rigió, dirigió y gobernó el Imperio musulmán bajo tres califas: su marido al-Madhi, tercer califa 'abasí, (775-785), después de cuya muerte acaecida de forma inesperada ocupó el poder, ya que sus dos hijos estaban lejos de Bagdad; durante el mandato de su hijo al-Hadi, y también durante el gobierno de su hijo menor, el conocido Harun

14 Cfr. Mernissi, F.: op. cit. p. 148.

15 Las mujeres yemenies nunca permitieron que sólo los hombres se ocuparan de la política. ¿A caso mantenían el recuerdo de la reina de Saba a pesar de la Islamización? 
al-Rasid, su preferido, quien, reconociendo los talentos de su madre, demostró al mundo musulmán que no se avergonzaba de compartir el poder con una mujer. Cuando ella murió, todos los súbditos se dieron cuenta de su valía y del gran amor que su hijo tenía hacía ella por el enorme dolor y tristeza que él sintió.

También durante el gobierno de los 'abbasies, encontramos que la madre del califa al-Muqtadir bilah (908-932), llamada Shaghad, actuó como regente y gobernó el imperio durante un tiempo, durante el cual estableció un juzgado y nombró a una mujer como responsable del mismo, pero al no acudir nadie a él por este nombramiento, el qadí Abul-Hasan hubo de manifestar que era correcto que una mujer estuviera a cargo del juzgado, después, todo el mundo comenzó a ir. Shaghad celebraba audiencias públicas en las cuales se presentaban demandas y se dictaminaba sobre asuntos criminales. Siendo ella misma la encargada de dictar los edictos una vez escuchados los jueces y los gobernadores ${ }^{16}$.

Posteriormente, durante el gobierno de los Selyuqies, en un momento en que el sultanato alcanzó su máximo esplendor ${ }^{17}$ y extensión, pues se extendía desde Kashgar hasta Damasco, y de modo efímero se acató su autoridad en el Yemen y en otras partes de Arabia, una mujer, Jatun Turkan, llamada la "Señora de Isfahan» ${ }^{18}$, trató de tomar el poder a la muerte de su marido el sultán Malik Shah (1072-1092), pues su hijo contaba tan sólo cuatro años, y es sabido que el Islam, como cuestión de principio, prohibe que se entregue el poder a un niño. Quiso llegar a un acuerdo con el califa 'abbasí que residía en Bagdad, pero éste no estaba dispuesto a permitir que una mujer se instalase en el trono, y el entonces califa, Al-Muqtadi, exigió que la jutba se hiciese en nombre del heredero ${ }^{19}$.

Otra mujer, Safiyya Jatun (1167-1242), hija del gobernador ayyubi de Alepo, al-Malik al-'Adil, administró el Estado en nombre de su nieto durante seis años. Se la recuerda por haber restablecido la justicia y la com-

16 Cfr. Bewley, A.: op. cit. pp. 48-49.

17 En la organización del imperio desempeñó un papel destacado, Nizam al-Mulk, visir que fue de su padre y de su abuelo. A él se debe la difusión de una innovación importante, que si bien no fue invención suya, recibieron de él su peculiar marca, se trataba de la madrasa, institución de enseñanza superior. La primera que se creó en Bagdad lleva su nombre "Nizamiyya" y fue el modelo de todas las fundaciones posteriores.

18 Cir. BewLEY, A.: Islam: el poder de las mujeres, p. 51.

19 El hecho de que se pronunciase el nombre en la jutba, oración de los viernes, y que se acuñase moneda en su nombre eran dos hechos fundamentales considerados como simbolos del poder. Y ello equivalia a un reconocimiento de la soberanía. 
pasión en su reinado, y de manera especial, por haber eliminado impuestos injustos ${ }^{20}$.

También en época ayyubí gobernó, a la muerte de su padre, en nombre de su hijo, Ghaziyya (1257) hija del sultán ayyubi, que contrajo matrimonio con el príncipe Hama. Se la describe como una mujer piadosa y modesta. ${ }^{21}$

Una mujer importante fue Shajarat Ad-Durr, "Árbol de las perlas", (1250) dotada de extraordinaria belleza y de gran inteligencia; leía mucho y le gustaba escribir. Ha sido considerada, por algunos, la fundadora del poder de los mamelucos en Egipto. Cuando murió su marido, Malik asSalih ${ }^{22}$, último soberano de la dinastía ayyubí, ella se hizo con el mando de la nueva dinastía.

Por entonces, el rey Luis IX de Francia dirigió la séptima cruzada (1248-1254) desembarcando en la costa de Egipto en el verano de 1249. Shajarat no sólo dirigió la resistencia sino que además aconsejó a su marido acerca de la forma en que deberían hacer frente a los cruzados y con buenas dotes de organización planeó la defensa. Pero la muerte le sorprendió a su marido en plena lucha con los cruzados, por lo que Shajarat negoció con los comandantes del ejército para mantener en secreto la muerte de su esposo con el fin de evitar una peligrosa intranquilidad política. Ella misma prosigue la lucha y logra capturar al monarca francés el 9 de febrero de 1250. A cambio de su liberación, Luis IX cedió Damietta y entregó un rescate de cuatrocientos mil dinares.

Cuando regresó a El Cairo Turan Shah, hijo de su esposo, Shajarat le confió el poder, pero éste dio pronto muestras de incapacidad para dirigir el ejército. A su muerte, los mamelucos se reunieron y acordaron nombrar a Shajarat soberana, único caso en la historia del Egipto musulmán, y le otorgaron el juramento de fidelidad el 14 de mayo de $1250^{23}$. El Imam pronunció la jutba en su nombre y las monedas se acuñaron en nombre de la "Reina de los Musulmanes" con esta inscripción: "Que Alá proteja a la Única y Benéfica Reina de los musulmanes, la bendita del mundo terrenal

20 La dinastía de los Ayyubíes (1171-1250) fue fundada por Saladino, quien a la muerte de Nur al-Din se apoderó de Damasco y Siria. A su muerte, 1193, sus estados se dividieron entre sus hijos y hermanos.

${ }^{21}$ Cfr. Bewley, A.: op. cit, p. 50.

22 Najm ad-din era hijo del sultán al-Kamin. Cuando éste murió, su hijo accedió al poder y se hizo Ilamar As-Salih a la edad de 34 años. Siendo príncipe se casó con Sagarat ad-Durr elegida por su belleza entre las jóvenes sirvientes que vivia en la fortaleza de Keyfa, puesto ayyubí en los confines del Turkestán.

23 Cfr. Bewley, A.: op. cit. pp. 48-49. 
y de la Fe, la madre de Jalil al Musta Simiyya, la compañera del sultán alMalik as-Salih".

No obstante, el califa 'abbasí, al-Mustasim, se negó a reconocerla por lo que ejército, a pesar de la admiración que sentía por Shajarat, se vio obligado a deponerla. Reinó ochenta días sin la autorización del califa. Shajarat resolvió el conflicto casándose con uno de los generales más poderosos del ejército, 'Azz ad-Din, y para no caer en el anonimato se aseguró que en todas las mezquitas de El Cairo se pronunciara la jutba en su nombre y en el de su esposo. $Y$ se aseguró también que las monedas se acuñasen con los nombres de ambos soberanos, y que los documentos oficiales llevasen la firma de ambos.

Sin embargo, su pasión amorosa la llevó a planear la muerte de su marido, convirtiéndose en una asesina. Para Shajarat el amor iba unido a la fidelidad, y no pudo soportar que su esposo decidiese tomar otra esposa, ya que pretendía casarse con la hija del rey de Mosul, Badr al-Din Lulu. Por lo cual ordenó su muerte mientras estaba en el hammam. Poco después, ella moría a manos de los esclavos de su marido,'Azz ad-Din. Su cadáver semidesnudo fue arrojado desde una elevada roca, y alli permaneció varios días hasta que le dieron sepultura. Fue enterrada en el patio de una escuela que ella había fundado y que hoy es conocida como la mezquita de Shajarat al-Durr en El Cairo. En su cúpula hay una larga inscripción que recuerda su reinado en sus días de grandeza y el título que ella apreciaba tanto: "La bendita del mundo terrenal y de la fe" ${ }^{24}$.

Ya en el siglo XIV, (1335) pero también durante el gobierno de los mamelucos, gobernó como ministra Baghdad Jatun bint an-Nuwan Chuban. Solía cabalgar en los desfiles con una espada colgada de la cintura y también consta que se ocupaba de emitir veredictos legales. ${ }^{25}$

Ya finalizando el siglo xv, 1479, el cronista del último periodo mameluco en Egipto, Ibn 'lyas, redactó el siguiente relato con ocasión de la muerte de la princesa Jawand Zaynab, única esposa del sultán Inal (14531461): "Tenía el rango de las princesas más nobles. Su prestigio durante el reinado de su marido era tan grande que administraba los asuntos del Estado, y ejercia una gran influencia sobre los nombramientos y las destituciones... mantuvo su honor hasta que murió a los ochenta años"». ${ }^{26}$

\footnotetext{
24 Cfr. Mernissi, F.: Las sultanas olvidadas, pp. 171-172.

25 Cfr. BEwLEY, A.: op. cit. p. 50.

26 Según señala Carl Petry, los historiadores de los periodos ayubies y mamelucos, 1171 1517, están descubriendo un grado de igualdad considerable entre los hombres y las mujeres durante aquella época, pero no está claro hasta que punto ocurría lo mismo en el resto de la sociedad.
} 
Contemporánea de Shajarat ad-Durr, pues sólo las separan catorce años en la toma del poder, otra mujer llamada Radhia, gobernó en Delhi, capital del gran reino musulmán de la India. Radhia, no era esclava como Shajatat, sino que era hija del sultán litutmish (1211-1236) ${ }^{27}$, y fue la única mujer que accedió al trono a la muerte de su padre estando soltera. Se hizo llamar Radiyya que significa «bendición» (rada) y tomó dos títulos: el primero era "Radiyya al-Dunyawa al-Din" "La bendita del mundo terrenal y la fe"; y el segundo fue el "Balqis Jihan", Balqis es el nombre árabe de la reina de Saba, y jihan, un título de nobleza. Fue el primero y único ejemplo de una mujer sultana en Delhi.

Uno de sus primeros actos de soberanía fue acuñar moneda en su nombre con la siguiente inscripción: «Pilar de las mujeres, reina de los tiempos, Sultana Radiyya Bint Shams al-Din Iltumish». Llama la atención, asimismo, la inscripción que aparece en una de sus monedas, porque habla de su alianza con la dinastía 'abbasí: "En tiempos del imám alMustansir Comandante de los fieles, Sultán todopoderoso, Esplendor del mundo y de la fe, Malika litutmish, hija del sultán Iltutmish, la que da gloria al Comandante de los fieles» ${ }^{28}$.

Era una mujer muy inteligente, ejerció una autoridad completa e incluso dirigió el ejército en las batallas. Según cuenta Ibn Battuta, una de las fuentes más antiguas que tenemos sobre Radhia, una vez que alcanzó el poder, una de sus primeras actuaciones fue quitarse el velo. No obstante, hubo de enfrentarse a los "cuarenta", especie de junta de los mayores feudatarios y oficiales del reino, y no pudiendo prevalecer contra ellos, fue derrocada en 1240, siendo sustituida por uno de sus hermanos, llamado Burham.

Pero Radhia no se resistió, organizó un ejército y se dirigió a Delhi vestida de hombre para recuperar lo que ella creía que era su derecho. El propio Ibn Battuta nos cuenta de ella que "gobernó como monarca absoluto durante cuatro años. Montaba como los hombres, armada de arco y carcaj; y no se cubría la cara". Otras fuentes dicen que se cortó el pelo y se vistió como un hombre... no sólo para dirigir las campañas militares, sino también para mantener el contacto con el pueblo. A ella le gustaba pasearse por el zoco y sentarse entre las gentes para escuchar sus quejas.

27 Iltutmish era un esclavo turco que llegó a ser uno de los más grandes reyes esclavos Fundó en 1229 el Estado musulmán de la India. Su legitimidad fue otorgada por el califa 'abbasí al-Mustansir (1226-1242).

28 Cfr. MERNISSI, F.: Las sultanas olvidadas, p. 156. 
Cumplió con sus deberes con gran competencia, se la consideró una buena administradora. Sin embargo, cometió un error que la gente no aceptó como fue el enamorarse de un esclavo abisinio, Jamal al-Din Yaqut, pues a pesar del Islamismo, el sistema de castas de la India se había impuesto. El ejército acordó deponerla, ella le hizo frente pero fue derrotada. No obstante, el gobernador Inkhtiyar al-Din Altuniyya, que se había enamorado de ella, la liberó de la prisión, y juntos combatieron de nuevo, pero fueron derrotados; el ejército se dispersó y Radiyya huyó. A su muerte fue enterrada según los ritos musulmanes. Su tumba existe a orillas del gran río Jamna, y sobre ella se construyó una cúpula que ahora se visita. Su reino había durado tres años, seis meses y seis días ${ }^{29}$. Ibn Battuta nos dice que el pueblo hizo de ella una santa.

$Y$, por otra parte, Firishita, historiador indio del siglo XVI dijo de ella: "La princesa estaba dotada de todas las cualidades que se requieren del rey más capacitado. Sus acciones fueron examinadas estrictamente sin que se encontrara en ella ningún fallo, excepto que era mujer. Durante el mandato de su padre, solía intervenir en los asuntos de gobierno, apoyada por su padre que veía en ella un gran talento para la política. En una ocasión la nombró regente mientras estaba fuera, e interrogado por el motivo por el cual no dejó a uno de sus hijos varones, respondió que sus hijos se dedicaban al vino, a las mujeres, al juego y a la adulación, y por estas razones el gobierno era una carga demasiado pesada para ellos. Añadió que Radiya, aunque era mujer, tenía la cabeza y el corazón de hombre y era mejor que veinte de sus hijos" ${ }^{30}$.

A su padre, lltutmish, que había sido esclavo y debía su ascenso a sus propias cualidades personales, no le constaba ningún esfuerzo reconocer el valor de una mujer. A sus ojos, el mérito y la justicia iban de la mano ${ }^{31}$.

A través de esta sucinta descripción hemos podido observar que Radiyya guarda ciertas semejanzas con Shajarat, ambas eran turcas, fueron ascendidas por sus propias gentes, pero las dos terminaron de igual manera: abandonadas por sus respectivos ejércitos y murieron debido a sus pasiones amorosas.

También entre los mongoles encontramos a mujeres reinando. Dos de ellas pertenecen a la dinastía Kutlugh-Janida que reinó en Kirmán, provincia persa situada al suroeste del desierto Dasht ilut. Una fue Jatun Turkan

\footnotetext{
Cfr. Amina Yagi, V. y Moalla, A.: Les figures de l'/s/am, p. 88

Cfr. BEWLEY, A.: op.cit. pp. 49-50.

Cfr. Mernissi, F.: Las sultanas olvidadas, p. 165
} 
a quien los mongoles confiaron el gobierno una vez que se quedó viuda de Qutb al-Din, en 1257, ya que tenía un hijo que era menor de edad, pues los notables de Kirmán pidieron a la corte mongola que confiara el gobierno a Jatun, quien llegó a reinar durante veintiséis años (1257-1282).

Fue una mujer muy inteligente y supo mantener buenas relaciones con la corte mongola. Casó a su hija, Jatun Padisah, con un hijo de Hulagu, quien la confirmó en su título y logró que en las mezquitas se proclamase la jutba en su nombre. Llevó el título de Ismat al-dunyawa al-din. Sin embargo, estando en el apogeo de su poder, Jatun Turkan hubo de hacer frente a los deseos de su hijastro, Suyurghatamish, hijo de su esposo muerto, que deseaba apoderarse del trono, pues no podía aceptar la idea de que su madrastra ocupase el gobierno. Para mantener la paz, Turkan se vio obligada a incluir su nombre con el suyo propio en la jutba, pero, a pesar de todo su esfuerzo, terminó perdiendo el trono. Posteriormente, seria su hija, Jatun Padisah, quien vengase su derrota.

Jatun Padisah fue una mujer muy culta, tras quedarse viuda se casó con Gayjatu, gobernante de la dinastía iljan, que llegó al poder en 1291, y a quien solicitó le entregase el trono de Kirmán como prueba de amor. El esposo accedió y Padisah ejerció como jefe de Estado. Recibió el título de "Safwat al dunyawa al din", "Pureza del mundo terrenal y de la fe». Hizo acuñar moneda de oro y plata con su nombre.

Otra reina que accedió al trono al estilo de Jatun Padisah, al casarse con un príncipe iljan, fue Jatun Absh que gobernó el reino persa durante casi veinticinco años (1263-1287). Su marido era uno de los hijos de Hulagu. Pertenecía a la dinastía sulghurí que tenía su capital en Shiraz. Ella fue la última soberana de esta dinastía que se había mantenido en el poder durante un siglo. En su nombre se proclamó la jutba de los viernes y se acuñaron monedas.

En condiciones similares llegó al poder Jatun Dawlat, soberana de la dinastía bani jursí, que gobernó Luristán durante casi cuatro siglos desde 1195. Dawlat ascendió al trono a la muerte de su marido, pero al no poder manejar los asuntos del Estado, cedió el gobierno a su cuñado.

Ibn Battuta quedó sorprendido por el respeto y la atención que se dedicaba a las mujeres a quienes los mongoles exhibian a su lado sin velo durante las ceremonias religiosas. A las jatuns dedicó varios capítulos en libro. ${ }^{32}$

32 Cfr.: Ibn BattutA, A través del islam, pp. 424-428 y 438-439; y MernisSi, F.: Las sultanas olvidadas, pp. 177-183. 
En otro lugar lejano, en el Yemen, encontramos a dos mujeres que gozaron del privilegio y del indiscutido criterio para ser reconocidas como jefes de Estado, como era el hecho de que en las mezquitas se pronunciara la jutba en su nombre. Una de ellas fue Asma bint Shihab alSulayhiyya, que gobernó el Yemen junto a su marido, Alí lbn Muhammad al-Sulayhi, fundador de la dinastía que lleva su nombre. Asma llamó la atención de los historiadores no sólo porque tuvo el poder, sino primero y ante todo porque "asistió a los consejos con cara descubierta", es decir sin velo; y además, porque desde los púlpitos de las mezquitas del Yemen se pronunciaba la jutba en su nombre y en el de su marido. Asma murió en 1087.

La otra mujer que también fue reina se llamó Arwa bint Ahmad al Sulayhiyya, y fue nuera de Asma. Dirigió el Yemen durante casi medio siglo (1091-1138). Una de las principales medidas que llevó a cabo fue el trasladó de la capital de San'a a Jibla, con ello cambió la dedicación que el país prestaba a las armas hacia la agricultura ${ }^{33}$. La jutba se pronunciaba en su nombre, y en ella se decía: “Que Alá prolongue los dias de al-Hurra (noble dama libre), la perfecta, la soberana que con tanto esmero se ocupa de los asuntos de los fieles". Se la recuerda con agrado.

Ambas reinas tenían el mismo título real "Al-sarrida al hurra", que significa "la noble dama libre e independiente", la noble dama que no se inclina ante ninguna autoridad superior. Desgraciadamente, su reino como el de su antecesora Asma, fue olvidado por muchos historiadores.

También encontramos a sultanas en las islas indias. Tres en las Maldivas, y cuatro en Indonesia, pero éstas corresponden ya al siglo XVI y siguientes. Por suerte para nosotros el famoso viajero lbn Battuta en el transcurso de sus viajes en el siglo XIV, describe su visita a las islas Maldivas, y nos habla de esas damas ${ }^{34}$. La primera sultana fue Jadiya bint 'Umar al-Bengali, hija del sultán Salah al- Din Salih Albendjaly, que reinó de 1347 a 1379 , y refiere precisamente que "una de las maravillas de estas islas es que la gobernante es una mujer". $Y$ hace hincapié en que el «orador menciona a la sultana en la oración del viernes y también en otras ocasiones".

Después de la muerte de Jadiya, que reinó treinta y tres años, ocupó el trono su hermana Myriam, y después la hija de ésta, la sultana Fátima, que gobernó hasta su muerte en 1383. De tal forma, que los musulmanes

Cfr. BewLeY, A.: op. cit. p. 51

${ }_{34}$ Cfr. Ibn Battuta, op cit, p. 662-682. 
de las islas Maldivas estuvieron gobernados por mujeres durante cuarenta años ${ }^{35}$.

Haciendo un pequeño inciso, recordemos que Ibn Battuta solía casarse durante sus viajes al mundo musulmán, y estando en las Maldivas no pudo resistirse mucho ante el encanto de las mujeres de estas islas, de tal modo que contrajo matrimonio con la madrasta de la sultana. Estuvo tan encantado con el tratamiento real que le dispensó su esposa que no vaciló en tener cuatro. $Y$ deja traslucir una gran pena cuando a su marcha a Tánger no puede llevarse a ninguna de ellas, así dice: "las mujeres de estas islas nunca abandonan su pais, y no he visto en el mundo mujeres cuya sociedad fuera más placentera. Una mujer de estas islas nunca confiará a nadie la atención de su marido, ella misma le lleva la comida, le retira los cubiertos, le lava las manos y le lleva agua para las abluciones y le hace masajes en los pies cuando se va a la cama". La única falta que encontró en las mujeres maldivas, especialmente en su papel de cadí, era que iban semidesnudas, "cuando fui cadí me esforcé en poner fin a esta práctica y ordené que las mujeres se vistieran, pero no logré nada" ${ }^{36}$.

También cuando Ibn Battuta pasó por Anatolia en el invierno de 13311332, y desde Bursa se dirigió a Yaznik (Nicea, act. iznik), describe esta ciudad y nos narra que era inexpugnable, pues el agua de la albufera la rodeaba por todas partes, y añade que en ella vivían pocos hombres al servicio del sultán, gobernados por su esposa, Bayalun Jatun, a la que califica de "excelente y virtuosa mujer", la cual le "honró, invitó y trató bien». ${ }^{37}$ Ibn Battuta anotó que entre los turcos «las mujeres disfrutaban de una posición más digna que la de los hombres». ${ }^{38}$

Junto a estas mujeres que llegaron a ejercer en cierta medida el poder en algunos lugares del Oriente islámico, podemos señalar también a otras mujeres que desde el ámbito de la Corte llegaron a influir notablemente en la vida política de! momento. Me estoy refiriendo a mujeres que fueron concubinas, madres o hijas en la Corte de las dinastías andalusíes o norteafricanas, cuyas actuaciones son calificadas por las Crónicas como «in-

\footnotetext{
35 Los geógrafos árabes nos dicen que las islas Dibajat, situadas entre la India y la Península Arábiga, estaban gobernadas por una mujer, una reina que vivia con gran esplendor. Los navegantes árabes cuentan que en la isla de Minicoy, situada entre las Maldivas y las Laquedivas, las mujeres estaban al mando de la comunidad y eran quienes tomaban las decisiones más importantes. El hombre tenía sólo la obligación de ofrecerles comida.

36 Cfr. Ibn BATTUTA, op. cit. p. 677 y Mernissi, F.: Las sultanas olvidadas, pp. 187-189.

37 Cfr. Ibn BATTUTA, op. cit. p. 400.

38 Cfr. BEWLEY, A.: op. cit. p. 54-55.
} 
trigas femeninas", según ha puesto de relieve $M^{\text {a }}$ Jesús Viguera en un reciente trabajo ${ }^{39}$.

En al-Andalus, hay que destacar la decisiva actuación de Subh, cautiva vascona, esposa del califa al-Hakam Il que llegó a alcanzar el rango de umm walad por ser la madre del príncipe heredero, el futuro califa Hisam II. Siendo prisionera de guerra supo ir escalando puestos relevantes por su belleza, inteligencia y cultura. Subh dominó el reinado de su hijo, débil e incapaz, hasta que Almanzor decide por sí mismo tomar las riendas del poder. Esta mujer llena de ambición ejerció su poder tanto indirectamente en vida de su marido, como ya de forma directa después de su muerte. Al igual que otras mujeres que lograron convertirse en favoritas, estaban bien informadas y conocian con precisión lo que sucedia en el reino. Para algunos esta mujer fue una "vulgar intrigante" que mantuvo durante treinta años relaciones con Almanzor.

También Al-Dalfa', viuda de Almanzor, calificada de "conspiradora", intervino y fomentó la gran revuelta política que terminaría con el Califato de Córdoba, para vengar la muerte de su hijo al-Muzaffar.

Dentro de las dinastías beréberes del norte de África, sobresalió Zaynab an-Nafzawiya, esposa del gobernador de los Almorávides, Yusuf b. Tasufin, cuyos dominios se extendían desde el norte de África hasta España. Las fuentes afirman que tenía su autoridad completa sobre las competencias del Estado y fue descrita como «aquella que está encargada del dominio del mundo". En las fuentes posteriores, de la época almohade, este hecho se interpretó como consecuencia de la dejadez masculina ${ }^{40}$.

A veces la influencia ejercida por una mujer, en este caso el de la madre, es reconocido por el propio hijo, como hizo el rey 'Abd Allah de Granada, quien no tuvo reparos en reconocer, como en otro momento vimos que hizo Harun al-Rasid, la importancia e influencia de su madre, quien tenía acceso y controlaba el Tesoro Real. El amor hacia su madre queda reflejado en el hecho que al abandonar Granada sólo se preocupó de llevarla a ella consigo, como lo refleja él mismo en sus Memorias: " $A$ / salir de Granada, en efecto, la idea de que podía ser encarcelado me hizo temer verme separado de mi madre, si la dejaba en el alcázar, y salí con ella, sin cuidarme de la suerte de nadie más". Fueron su persona y la de

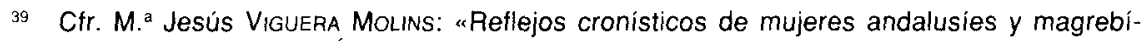
es", en Anaquel de Estudios Árabes. Homenaje a I a profesora Dna. Soledad Gibert Fenech, 12, 2001, pp. 829-841.

${ }_{40}$ AL-MARRAKuSI, cronista contrario a los Almorávides, destaca en el Mu'yib, la intervención de

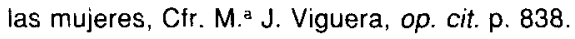


su madre lo único que no fue considerado por los Almorávides como botín cuando le ordenan salir de Granada. 'Abd Allah confiesa su sufrimiento ante el temor de perder a su madre, cuando fue requerida para subir al alcázar para proceder a retirar los tesoros, "ausencia que me amargó durante varios días, de los cuales ni en uno solo dejé de pensar en que no volvería”.

El control que la madre de 'Abd Allah tenía del Tesoro la llevó a esconder algunas de sus riquezas por "temor a quedarse pobres ya que la muerte es más llevadera que la pobreza»; pero al ser amonestada por su hijo no tuvo más remedio en confesar cuáles habían sido los efectos que había depositado la noche anterior a la rendición en manos de algunas esclavas ${ }^{41}$.

Asimismo fueron famosas las intrigas de la esposa favorita del rey nazarí Yusuf $\mathrm{I}$, que consiguió derribar a Muhammad $\mathrm{V}$ y proclamar sultán a Isma'il, su propio hijo. O la no menos conocida actuación de la sultana madre de Boabdil ${ }^{42}$, cuyas intrigas para destronar a su infiel marido, Muley Hacén fueron famosas.

Dejamos expuestas estas líneas para continuar en un futuro, pues aún queda mucho por hacer, teniendo en cuenta que las fuentes no han sido explotadas con la amplitud de datos que contienen, no sólo en lo referente a la mujer musulmana vinculada al poder, sino respecto a la historia de la mujer arabomusulmana en toda su extensión.

${ }^{41}$ Cfr. El siglo xi en $1 .{ }^{\text {a }}$ persona. Las "Memorias" de 'Abd Allah, último rey ziri de Granada, destronado por los Almorávides (1090). Trad. de E. Levi-Provençal y E. GARCiA Gómez, Madrid, 1980, pp. 272-275.

42 Tradicionalmente llamada 'A'isa, e identificada por E. de SAntiago Simón como Fátima. Cr. SANTIAGO SIMÓN, E. de: "Algo más sobre la sultana madre de Boabdil», en Homenaje al profesor D.Cabanelas, 1987, pp. 489-495. Véase también Seco LuCENA, L.: “La sultana madre de Boabdil”, en Al-Andalus, XII, 1947. 